\title{
Analysis of Facial Height between Prepubertal and Postpubertal Subjects in Rivers State, Nigeria
}

\author{
B. O. Akinbami ${ }^{1,2}$ and Mark Ikpeama ${ }^{1}$ \\ ${ }^{1}$ Department of Human Anatomy, University of Port Harcourt, Port Harcourt, Nigeria \\ ${ }^{2}$ Department of Oral and Maxillofacial Surgery, University of Port Harcourt, Port Harcourt, Nigeria
}

Correspondence should be addressed to B. O. Akinbami; akinbamzy3@yahoo.com

Received 27 March 2013; Revised 31 May 2013; Accepted 2 June 2013

Academic Editor: Kaushik Bose

Copyright (C) 2013 B. O. Akinbami and M. Ikpeama. This is an open access article distributed under the Creative Commons Attribution License, which permits unrestricted use, distribution, and reproduction in any medium, provided the original work is properly cited.

\begin{abstract}
Background. Appropriate craniofacial growth is vital both for aesthesis and normal growth of the brain. Cranial indices and facial heights are relevant parameters that are useful for anthropometric analyses of the growth of the entire craniofacial skeletal complex. The aim of this study was to determine differences in facial heights between prepubertal and postpubertal subjects. Method. The study consists of four hundred subjects, two hundred males and two hundred females who were selected at random on the ages ranging 12-16 and 17-25 years and were categorized into prepubertal and postpubertal. The facial parameters that were measured were upper facial height, lower facial height, and posterior facial height. Result. There was no significant difference found in the upper facial height between prepubertal and postpubertal females $(P>0.005)$. Conclusion. This study has shown that facial parameters are sexually dimorphic between male and female subjects and that male facial dimension was significantly higher than that of females. Also, it has been established that prepubertal subjects had higher facial dimension compared to corresponding postpubertal subjects.
\end{abstract}

\section{Introduction}

The craniofacial complex is divided into three and these include the cranium, upper face, and the lower face [1]. Facial aesthetic appreciation by the human mind is closely related proportions of the component portions in harmony [2]. This is because discrepancies or alterations in craniofacial proportions result in facial/body dimorphic syndromes in certain individuals especially when it far deviates from acceptable norms for a particular ethnic or racial population [3-5]. However, the growth of the upper and lower jaw is determined by the growth of the base of the skull. Failure of the cranium and base of the skull to increase in size causes a remarkable decrease in the size of the maxilla and mandible [6]. It is generally established in the literature that growth and discrepancies in sizes are under both genetic and environmental influence of which hormonal factor plays a significant role [7]. There are significant differences in hormonal levels at different stages of life [8]. The expectation is that, with such changes in hormonal levels especially the sex and growth hormones, there may be corresponding changes in anthropometric craniofacial parameters in various age groups. The purpose of our study was therefore to determine differences in facial heights between prepubertal and postpubertal subjects.

\section{Materials and Methods}

This was a randomized cross-sectional study which involved prepubertal and postpubertal subjects and was conducted in the Department of Anatomy, University of Port Harcourt, Rivers State, south-south geopolitical zone of Nigeria, between July 2012 and October 2012. Ethical clearance was obtained from the Research and Ethics and Committee of the College of Health Sciences, University of Port Harcourt, as well as informed consent from each subject before inclusion. The study consists of a total of four hundred subjects, two hundred males (one hundred belong to the prepubertal 
which was $12-16$ yrs of age group and one hundred to the postpubertal, 17-25 yrs of age group). Similarly 200 females were selected. The age selection was based on differences in hormonal levels before and after puberty. Individuals with craniofacial abnormalities as in craniosynostosis, sickle cell disease, and other syndromes affecting the craniofacial morphology were excluded. Also individuals below 12 were excluded because these were much younger children whose parameters are obviously lower and for individuals above $25 \mathrm{yrs}$; complete fusion of the epiphysis plates had already set in.

The materials used for this study include

(i) electronic digital caliper,

(ii) paper,

(iii) pen,

(iv) calculator,

(v) methylated spirit and cotton wool.

The facial parameters were taken based on standardized methods $[9,10]$. These include the following.

Upper Facial Height (UFH). Using the digital caliper, this was measured as the distance between the glabella and the nasal sill.

Lower Facial Height (LFH). Using the digital caliper, this was measured as the distance between the nasal sill and the chin.

Posterior Facial Height (PFH). This was also measured as the distance from the tragus of the ear and the soft tissue around the angle of the mandible.

(i) The subjects were asked to sit upright with head unsupported, relaxed, and breathe quietly as measurements were taken to prevent errors from soft tissue contractions.

(ii) The previous landmarks, that is, the glabella, nasal sill, chin, tragus, and soft tissue around the angle of the mandible were indicated with a pen marker. This allows point-to-point measurement and prevented intraassessor errors.

(iii) The digital caliper was set on the $0.00 \mathrm{~mm}$ before each reading was taken to ensure standardization of the measuring tool.

(iv) The upper, lower, and posterior facial heights for each subject was taken and recorded.

(v) Then the digital caliper was cleaned with cotton wool soaked in methylated spirit after each measurement. We followed universally accepted measurements for anthropological studies which are usually done with calipers with 2 pointed ends and distances between the ends were measured.

(vi) Measurements were made twice to ensure consistency and accurate readings taken by one but the same person for all the subjects to avoid interassessor errors.
The person is one of the authors. With the indication of the landmarks with pen markers, accuracy was ensured and since heights are continuous/parametric measurements, values of a single assessor are valid.

(vii) It was ensured that subjects did not laugh, talk, chew, or smile during the measurements to avoid errors.

(viii) Measurements were accident free exercise by observing some level of carefulness to avoid injury bearing in mind that the caliper had pointed ends.

(ix) Error due to parallax was avoided while taking readings from the digital caliper.

The data collected were analyzed using descriptive statistics (mean, ranges, and standard deviation) and comparison between prepubertal and postpubertal groups was done using $t$-test. All these were done with the statistical software, SPSS version 16 (SPSS Inc.) Illinois, Chicago.

\section{Results}

The distribution of the subjects according to specific ages and ranges of the facial height values are shown in Tables 1 and 2. To a large extent, males generally have higher heights than females for most of the ages.

The results on Table 3 showed higher mean values for $\mathrm{UPH}$ and PFH in prepuberty males than postpuberty males. There were significant differences between prepubertal and postpubertal males in upper facial heights and posterior facial heights $(P<0.05)$. However, no significant difference was found in the lower facial heights between prepubertal and postpubertal males $(P>0.05)$.

In Table 4, mean values were higher for the three heights in females in pre puberty ages compared to postpubertal females. There was significant difference between prepubertal and postpubertal females in their lower facial height and posterior facial height $(P<0.05)$. However, there was no significant difference found in the upper facial height between prepubertal and postpubertal females $(P>0.05)$.

The range (difference between maximum and minimum) values have been pictorially represented in Figure 1. UFH and $\mathrm{PFH}$ were higher for pre puberty males than post puberty males.

The range values have been pictorially represented in Figure 2. Range values were lower in the three heights in the pre puberty females than post puberty females.

\section{Discussion}

This study gave an insight into the facial height between prepubertal and postpubertal subjects in Rivers State, southsouth, Nigeria. The relative positions of the spatial relations of the nose, lips, and chin are contributors to the skeletal tissues to achieve a balanced facial profile. Measurement of the face showed that males in comparison with females had wider and higher faces, bigger minimal frontal breadth, and upper facial depth [11]. Underdevelopment of the jaws can also result in psychological problems and local effects such as excessive pressure on the temporomandibular joint. Stress 
TABLE 1: Distribution based on age and ranges of facial height values of 100 prepubertal females and 100 prepubertal males (12-16 yrs).

\begin{tabular}{lcccccccc}
\hline \multirow{2}{*}{ Age } & \multicolumn{3}{c}{ Female $(100)$} & \multicolumn{3}{c}{ Male $(100)$} \\
& $N(\%)$ & UFH $(\mathrm{mm})$ & LFH $(\mathrm{mm})$ & PFH $(\mathrm{mm})$ & $N(\%)$ & UFH $(\mathrm{mm})$ & LFH $(\mathrm{mm})$ & PFH $(\mathrm{mm})$ \\
\hline 12 yrs & $3(3)$ & $56.96-64.33$ & $49.50-55.19$ & $60.44-75.93$ & $5(5)$ & $54.99-65.69$ & $58.96-62.66$ & $55.46-75.78$ \\
13 yrs & $18(18)$ & $53.61-68.76$ & $49.89-64.43$ & $63.07-75.45$ & $17(17)$ & $53.47-70.02$ & $52.55-64.29$ & $53.98-84.91$ \\
14 yrs & $24(18)$ & $56.08-72.92$ & $52.52-72.70$ & $63.66-77.51$ & $24(24)$ & $57.48-66.33$ & $54.05-72.55$ & $56.56-83.59$ \\
15 yrs & $37(37)$ & $56.15-74.55$ & $50.41-65.01$ & $61.94-79.45$ & $38(38)$ & $54.28-68.02$ & $56.15-70.67$ & $59.87-79.48$ \\
16 yrs & $18(18)$ & $56.84-65.70$ & $52.56-70.97$ & $58.34-73.34$ & $16(16)$ & $59.31-74.43$ & $53.68-71.87$ & $65.57-78.72$ \\
\hline Total & 100 & $53.61-74.55$ & $49.50-72.70$ & $58.34-79.45$ & 100 & $53.47-74.43$ & $52.55-72.55$ & $53.98-84.91$ \\
\hline
\end{tabular}

TABLE 2: Distribution based on age and ranges of facial height values of 100 postpubertal females and 100 postpubertal males (17-25 yrs).

\begin{tabular}{lcccccccc}
\hline \multirow{2}{*}{ Age } & \multicolumn{3}{c}{ Females $(100)$} & \multicolumn{3}{c}{ Males $(100)$} \\
& $N(\%)$ & UFH $(\mathrm{mm})$ & LFH $(\mathrm{mm})$ & PFH $(\mathrm{mm})$ & $N(\%)$ & UFH $(\mathrm{mm})$ & LFH $(\mathrm{mm})$ & PFH $(\mathrm{mm})$ \\
\hline $17 \mathrm{yrs}$ & $11(11)$ & $51.24-64.39$ & $49.50-63.40$ & $49.42-67.91$ & $14(14)$ & $54.99-68.68$ & $52.21-69.08$ & $55.80-80.62$ \\
$18 \mathrm{yrs}$ & $3(3)$ & $57.21-58.60$ & $51.76-57.85$ & $64.84-65.32$ & $8(8)$ & $58.71-64.80$ & $58.18-63.83$ & $62.71-69.94$ \\
$19 \mathrm{yrs}$ & $5(5)$ & $57.60-59.60$ & $51.85-62.31$ & $59.46-72.11$ & $5(5)$ & $56.32-62.76$ & $53.68-60.50$ & $59.51-70.07$ \\
$20 \mathrm{yrs}$ & $15(15)$ & $47.21-65.92$ & $40.55-68.21$ & $53.51-73.12$ & $10(5)$ & $54.59-64.76$ & $57.71-66.27$ & $59.81-69.71$ \\
$21 \mathrm{yrs}$ & $15(15)$ & $60.12-63.86$ & $56.23-63.71$ & $51.92-77.70$ & $5(5)$ & $62.31-66.29$ & $54.72-60.96$ & $66.42-70.10$ \\
$22 \mathrm{yrs}$ & $8(8)$ & $44.68-67.80$ & $42.99-68.48$ & $51.18-72.28$ & $17(17)$ & $55.83-65.86$ & $56.08-67.47$ & $58.92-74.15$ \\
$23 \mathrm{yrs}$ & $24(24)$ & $53.16-60.45$ & $50.51-59.47$ & $61.26-69.26$ & $8(8)$ & $56.88-64.91$ & $59.54-75.59$ & $62.04-70.52$ \\
$24 \mathrm{yrs}$ & $7(7)$ & $53.95-69.17$ & $41.12-64.83$ & $57.25-65.16$ & $16(16)$ & $57.38-69.32$ & $60.59-70.45$ & $61.79-83.59$ \\
$25 \mathrm{yrs}$ & $12(12)$ & $57.80-67.81$ & $44.68-69.26$ & $51.52-77.91$ & $16(16)$ & $56.50-68.21$ & $58.95-71.04$ & $58.58-78.49$ \\
\hline Total & 100 & $44.68-69.17$ & $40.55-69.26$ & $49.42-77.91$ & 100 & $54.59-69.32$ & $52.21-75.59$ & $55.80-83.59$ \\
\hline
\end{tabular}

TABLE 3: Range, mean and standard deviation values of facial height of 100 prepubertal males and 100 postpubertal males.

\begin{tabular}{|c|c|c|c|c|}
\hline Parameter & $\begin{array}{l}\text { Prepubertal } \\
\text { males }(\mathrm{mm})\end{array}$ & $\begin{array}{l}\text { Postpubertal } \\
\text { males }(\mathrm{mm})\end{array}$ & $\begin{array}{c}\text { Significance } \\
\text { value } \\
P \text { value set } \\
\text { at } 0.05\end{array}$ & Inference \\
\hline $\begin{array}{l}\text { Upper facial } \\
\text { height }\end{array}$ & $\begin{array}{l}53.47-74.43 \\
62.96 \pm 3.92\end{array}$ & $\begin{array}{l}54.59-69.32 \\
61.66 \pm 3.37\end{array}$ & 0.012 & Significant \\
\hline $\begin{array}{l}\text { Lower facial } \\
\text { height }\end{array}$ & $\begin{array}{l}52.55-72.55 \\
62.17 \pm 4.59\end{array}$ & $\begin{array}{l}52.21-75.59 \\
62.81 \pm 4.74\end{array}$ & 0.33 & $\begin{array}{c}\text { Not } \\
\text { significant }\end{array}$ \\
\hline $\begin{array}{l}\text { Posterior } \\
\text { facial height }\end{array}$ & $\begin{array}{l}53.98-84.91 \\
69.97 \pm 5.81\end{array}$ & $\begin{array}{l}55.80-83.59 \\
67.62 \pm 4.87\end{array}$ & 0.002 & Significant \\
\hline
\end{tabular}

$P<0.05$ is considered significant.

TABLE 4: Range, mean and standard deviation values of facial heights of 100 prepubertal females and 100 postpubertal females.

\begin{tabular}{|c|c|c|c|c|}
\hline Parameter & $\begin{array}{l}\text { Prepubertal } \\
\text { females } \\
\quad(\mathrm{mm})\end{array}$ & $\begin{array}{l}\text { Postpubertal } \\
\text { females } \\
(\mathrm{mm})\end{array}$ & $\begin{array}{c}\text { Significance } \\
\text { value } \\
P \text { value set } \\
\text { at } 0.05\end{array}$ & Inference \\
\hline $\begin{array}{l}\text { Upper facial } \\
\text { height }\end{array}$ & $\begin{array}{l}53.61-74.55 \\
62.16 \pm 3.98\end{array}$ & $\begin{array}{l}44.68-69.17 \\
61.26 \pm 4.94\end{array}$ & 0.16 & $\begin{array}{c}\text { Not } \\
\text { significant }\end{array}$ \\
\hline $\begin{array}{l}\text { Lower facial } \\
\text { height }\end{array}$ & $\begin{array}{l}49.50-72.70 \\
59.03 \pm 4.25\end{array}$ & $\begin{array}{l}40.55-69.26 \\
55.66 \pm 6.95\end{array}$ & 0.00 & Significant \\
\hline $\begin{array}{l}\text { Posterior } \\
\text { facial height }\end{array}$ & $\begin{array}{l}58.34-79.45 \\
70.23 \pm 4.47\end{array}$ & $\begin{array}{l}49.42-77.91 \\
62.91 \pm 6.70\end{array}$ & 0.00 & Significant \\
\hline
\end{tabular}

can further aggravate these problems because some people subconsciously clench and grind their teeth [12].

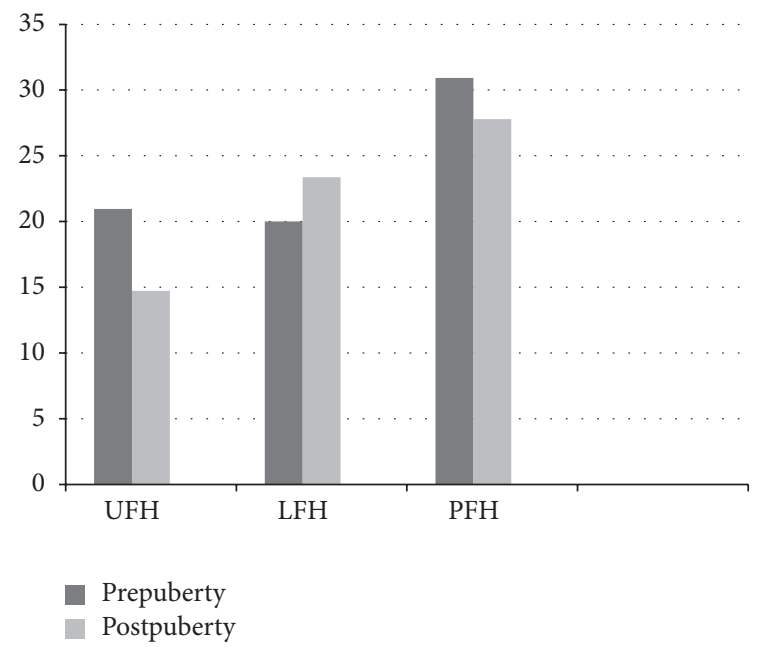

FIGURE 1: Range values for facial height between 100 prepuberty males and 100 postpuberty males.

Our findings suggest that facial height is sexually dimorphic and depends on sex hormones which are thought to be the main regulators of sexual dimorphism in physical features in males and females; prepubertal subjects had higher facial dimension compared to postpubertal subjects which suggests that sex hormones during puberty can influence growth rate pattern and facial height for the corresponding subjects. Prenatal testosterone concentrations are thought to modify development rate [8]. From the results obtained, it is suggested that early organizational effect of sex hormones 


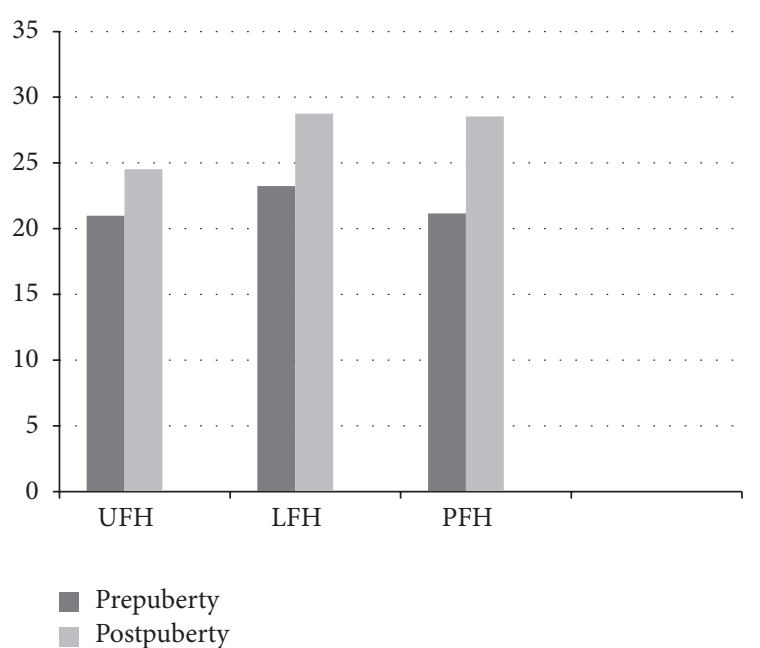

FIgURE 2: Range values for facial height between 100 prepuberty females and 100 postpuberty females.

through the association between indices of body shape, body mass index (BMI), and human growth pattern influenced the facial parameters [13].

The result of our study showed that values of the facial heights obtained for males were found to be higher than the corresponding female values. This corroborates earlier investigations $[5,10]$. Mean values and range values were more consistent in males than females generally; pre puberty males had higher mean and range values than post puberty males for upper facial and posterior facial heights. This may be a result of the random nature of selection of the subjects or it could actually be a reflection of the increased level of hormonal fluctuations in females compared to males at all phases of life but more especially around the menarche/puberty period [13].

For subjects in the pre puberty ages to record higher values than post puberty, it is shown that hormonal levels at that age bracket are usually higher than that at the postpubertal age group. This however did not reflect for the lower values of lower facial height in prepubertal males, which was difficult to explain but may not be unrelated to the differential apposition in growth of the various endochondral ossification sites in the mandible, 2 anterior, present in the (symphysis and alveolar arch) and 2 posterior (condyle and coronoid). Influence of hormones on these growth centers may also be different [14]. Maxillary growth responsible for increases in upper facial height is purely membranous while mandibular growth is both mainly membranous but with substantial contribution from endochondral ossification [15].

This study included subjects from the African Negro population; a similar study in a different population group will enhance thorough comparison of such parameters. Radiological assessment with CT scans or cephalometry analysis may further consolidate the accuracy of these findings [16]. Orthodontists, orthognathic, maxillofacial, and reconstructive surgeons will benefit from the results of this study when attempting to give patients a close to normal or ideal occlusion and esthetic facial profiles. In addition, many individuals, especially young adults are very conscious of their facial appearance and are fond of peer comparisons; this occasionally result in some paranoid tendencies; [17] therefore mean values obtained for both groups under consideration in this study will assist us to establish a basis of comparison.

In conclusion, we compared the mean and range values of upper facial, lower facial, and posterior facial heights in the prepubertal and postpubertal age brackets of both genders and we found that prepubertal values were higher in males for the UFH and PFH and not significantly different for $\mathrm{LFH}$, and mean values and range values were also more consistent for males than females. The main distinguishing highlight of this study from other studies is the analysis of these facial parameters in two different age brackets closely related to puberty and the establishment of the fact that facial dimensions do not necessarily increase as age increases.

\section{Conflict of Interests}

The authors hereby declare that none had any conflict of interests with regard to this research. They also declare that neither one of them has a direct financial relation that can cause any conflict with the commercial identities like SPSS, mentioned in their paper.

\section{References}

[1] C. S. Sinnatamby, Last's Anatomy, Harcort Publishers, 10th edition, 1999.

[2] J. Rabanus, "Smile proportions, Golden proportions," 2003, http://www.aesthetic-dentistry.com/.

[3] F. A. Basciftci, T. Uysal, and A. Buyukerkmen, "Craniofacial structure of Anatolian Turkish adults with normal occlusions and well-balanced faces," American Journal of Orthodontics and Dentofacial Orthopedics, vol. 125, no. 3, pp. 366-372, 2004.

[4] K. A. Phillips, S. L. McElroy, P. E. Keck Jr., J. I. Hudson, and H. G. Pope Jr., "A comparison of delusional and nondelusional body dysmorphic disorder in 100 cases," Psychopharmacology Bulletin, vol. 30, no. 2, pp. 179-186, 1994.

[5] F. B. Quinn, Preoperative Evaluation of the Aesthetic Patient. Grand Rounds Presentation, UTMB, Dept. of Otolaryngology, 2004.

[6] P. A. Lines, R. R. Lines, and C. A. Lines, "Profilemetrics and facial esthetics," American Journal of Orthodontics, vol. 73, no. 6, pp. 648-657, 1978.

[7] J. C. Kolar and E. M. Salter, "Craniofacial Anthropometry: Practical Measurement of the Head and Face for Clinical, Surgical, and Research Use," C. C. Thomas, Springfield, Ill, USA, 1997.

[8] B. S. McEwen, "Neural gonadal steroid actions," Science, vol. 211, no. 4488, pp. 1303-1311, 1981.

[9] E. Nagle, U. Teibe, and D. Kapoka, "Craniofacial Anthropometry in a group of healthy Latvian residents," Acta Medica Lituanica, vol. 12, no. 1, pp. 47-53, 2005.

[10] B. C. Didia and D. V. Dapper, "Facial, nasal, maxillary, mandibular and orofacial heights of adult Nigerians," OJM, vol. 17, no. 1-2, pp. 1-8, 2005.

[11] L. G. Farkas, T. A. Hreczko, J. C. Kolar, and I. R. Munro, "Vertical and horizontal proportions of the face in young adult North American Caucasians: revision of neoclassical canons," Plastic and Reconstructive Surgery, vol. 75, no. 3, pp. 328-337, 1985. 
[12] Y. Jefferson, "Facial proportions and human health," Journal of General Orthodontics, vol. 7, no. 2, pp. 250-273, 1996.

[13] M. L. Collaer and M. Hines, "Human behavioral sex differences: a role for gonadal hormones during early development?" Psychological Bulletin, vol. 118, no. 1, pp. 55-107, 1995.

[14] K. L. Moore and A. F. Dalley, Head and Neck; Clinically Oriented Anatomy, Lippincott-Williams and Wiilkins, Philadelphia, $\mathrm{Pa}$, USA, 1999.

[15] R. M. Ricketts, "Esthetics, environment, and the law of lip relation," American Journal of Orthodontics, vol. 54, no. 4, pp. 272$289,1968$.

[16] G. B. Scheideman, W. H. Bell, H. L. Legan, R. A. Finn, and J. S. Reisch, "Cephalometric analysis of dentofacial normals," American Journal of Orthodontics, vol. 78, no. 4, pp. 404-420, 1980.

[17] H. Peck and S. Peck, "A concept of facial esthetics," The Angle Orthodontist, vol. 40, no. 4, pp. 284-318, 1970. 

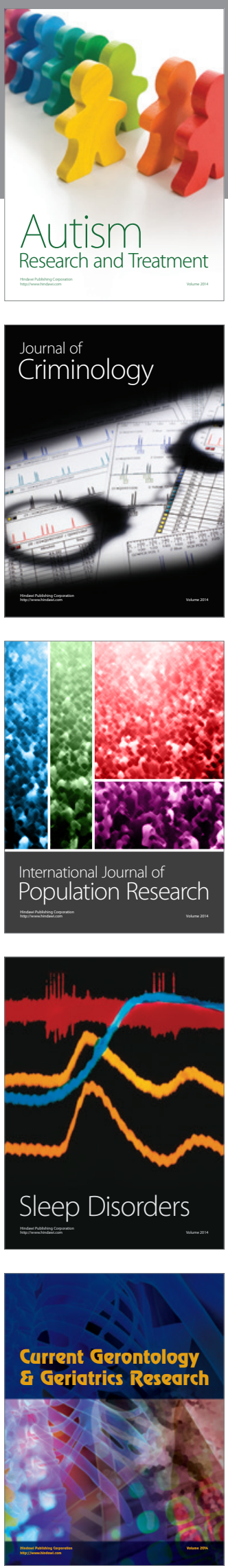
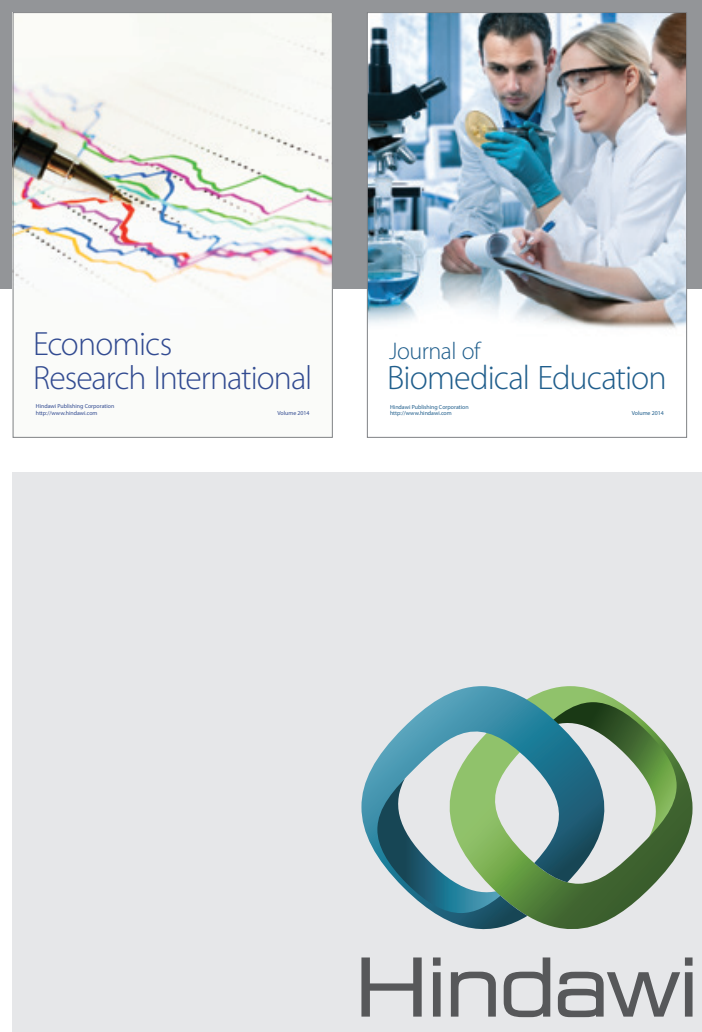

Submit your manuscripts at

http://www.hindawi.com
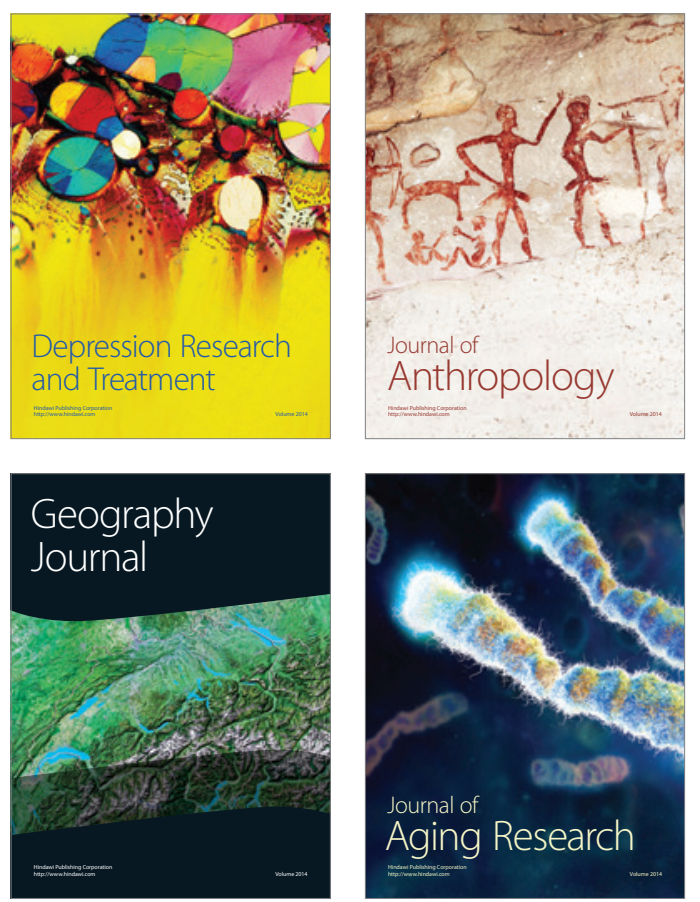
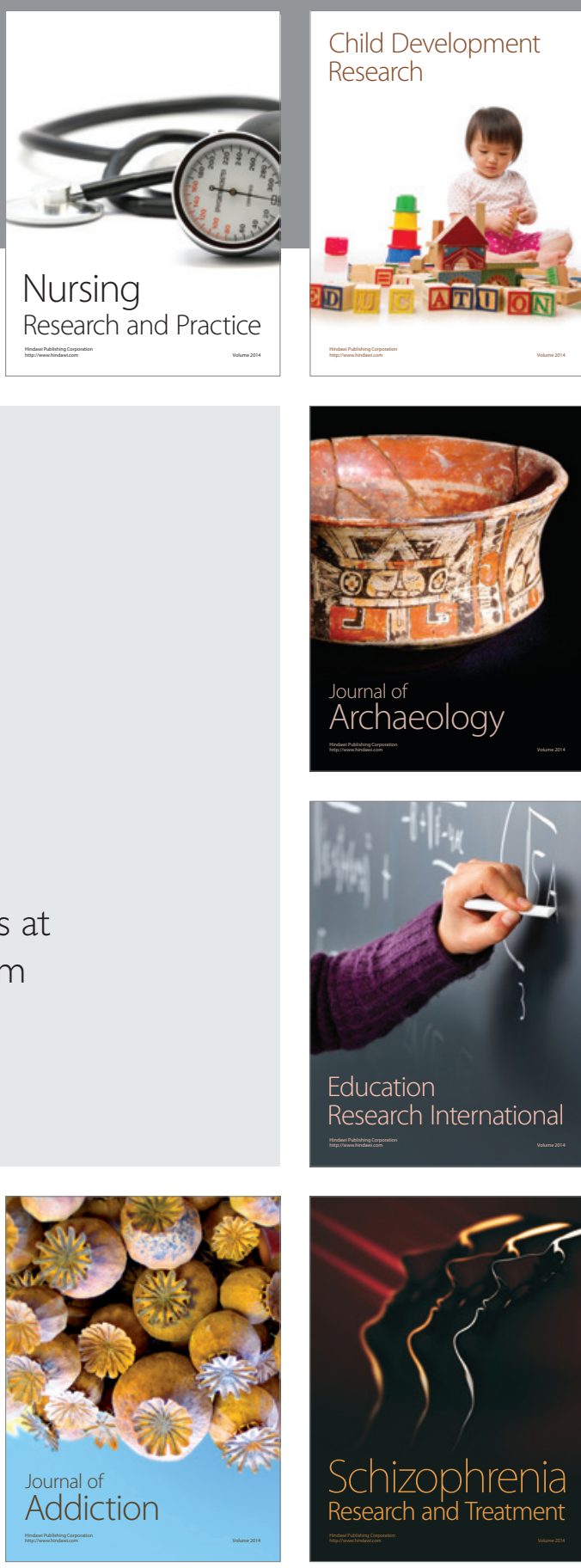

(D)
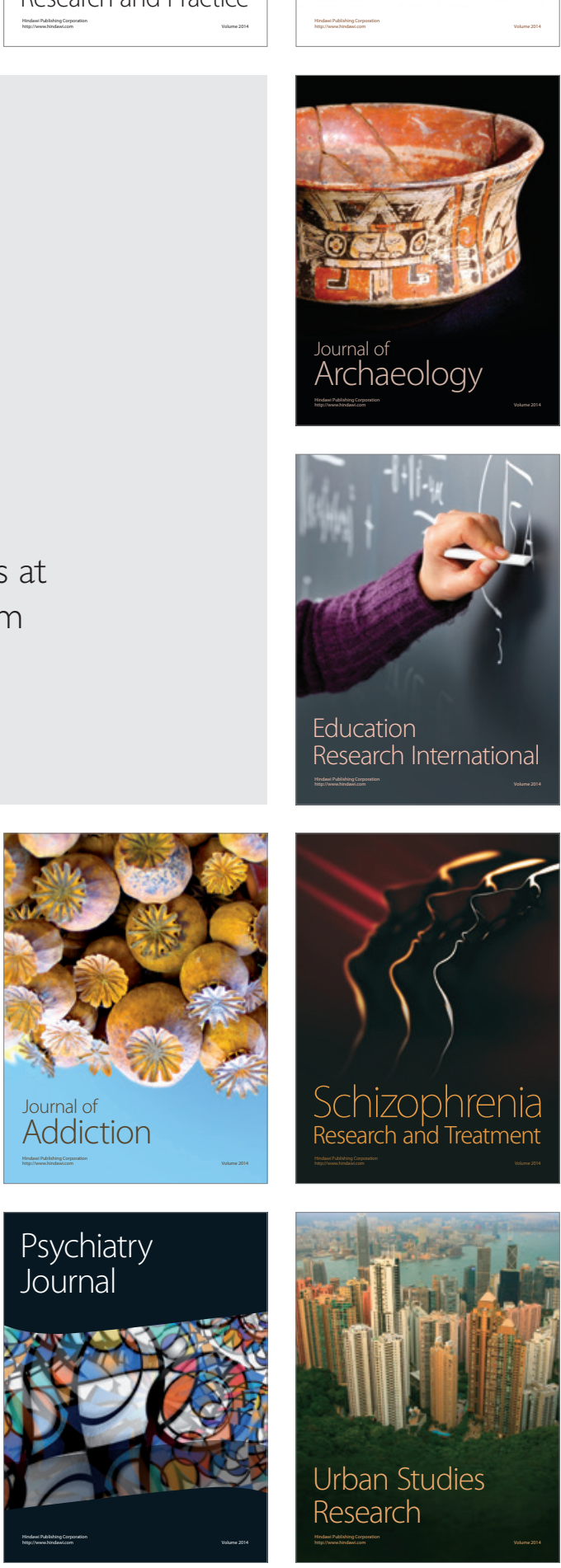